\title{
Experimental Study on the Formation and Characteristics of Mud Filtration Cake in Large-Diameter Slurry Shield Tunneling
}

\author{
Lei Kou $\left(D,{ }^{1}\right.$ Jinjie Zhao, ${ }^{1}$ Fanglei Lian, ${ }^{2}$ and Ronghu Miao' \\ ${ }^{1}$ School of Water Conservancy Science and Engineering, Zhengzhou University, Zhengzhou 450001, Henan, China \\ ${ }^{2}$ Henan Yellow River Bureau, Xinxiang Yellow River Bureau, Xinxiang 453003, Henan, China \\ Correspondence should be addressed to Lei Kou; klyhe@163.com
}

Received 27 December 2020; Revised 24 July 2021; Accepted 12 August 2021; Published 10 September 2021

Academic Editor: Mingfeng Lei

Copyright (ㅇ 2021 Lei Kou et al. This is an open access article distributed under the Creative Commons Attribution License, which permits unrestricted use, distribution, and reproduction in any medium, provided the original work is properly cited.

Multiple soil layers may be exposed simultaneously on the excavated surface of a large-diameter slurry shield. To study the formation and characteristics of mud filtration cake on the excavation surface during large-diameter slurry shield tunneling, penetration tests of mud slurries in different soils were carried out using a self-made device, and the microstructures of different mud filtration cakes were observed using scanning electron microscopy. The test results showed that there were three categories of filling forms for mud slurries permeating the soils: mud filtration cake, mud cake + permeation zone, and permeation zone; correspondingly, there were three types of filtration loss, which was mainly affected by the specific gravity of mud slurry. Finally, the porosity and the fractal dimension for the pore area of the mud filtration cake were calculated, and it is found that the fractal dimension of pore area is beneficial to classify the type of mud filtration cake.

\section{Introduction}

Large-diameter slurry shields are widely used in urban tunnel engineering and sea- (or river-) crossing traffic tunnel engineering [1-3]. During shield construction, the mud slurry penetrates soil and forms a mud filtration cake on the excavation surface, which can balance the pressure of water and soil in the ground; thus, the excavation surface is stabilized. Many scholars have carried out a lot of valuable research studies on effects of soil properties on the formation of mud filtration cake [4-7]. Watanabe and Yamazaki [8] conducted a mud cake formation test in a high permeability soil and found that the increase of mud density can effectively reduce slurry filtration loss. Yang et al. [9] studied the influence of bentonite content on the properties of seawater slurry, and the results showed that the specific gravity and viscosity of seawater slurry increased with the increase of the bentonite content, and the slurry filtration loss decreased with the increase of the bentonite content. Wei et al. [10] found that the type of mud membrane formed transits from mud cake to permeable mud cake zone with the increase of the diameter rate of strata soil and bentonite clay until an inability to form mud membrane in the same strata of the soil. Talmon et al. [11] carried out formation tests of mud filtration cakes on a sand layer with a porosity of 0.35 . The results indicated that a skin-type mud filtration cake would form when the ratio of the coarse grain diameter to the pore diameter was greater than $1 / 3$; a permeable zone-type mud filtration cake would form when the ratio of the coarse grain diameter to the pore diameter was greater than $1 / 7$ and less than 1/3. Min et al. [12] studied the formation of mud filtration cake for slurry shield tunneling in high permeable sand and found that the ratio between the average pore size of soil and corresponding particle size with a weight ratio of $85 \%$ in the slurry may be used to classify the type of mud cake formation.

Mud slurry properties have a significant impact on the quality of the mud filtration cake [13]. Min et al. [14] conducted mud cake formation tests of different muds in formations with a permeability coefficient of $10^{-4} \mathrm{~m} / \mathrm{s}$, and it was clear that the clay content in the mud has an important effect on the filter cake quality. Ye et al. [15] found that the thickness of the mud cake increases with the increase of the relative density of the mud, but it is not greatly affected by 
the viscosity of the mud. Wang et al. [16] conducted a simulation test on the stability of the excavation surface of the subsea tunnel and found that by increasing the clay content in the mud slurry and the viscosity of the mud slurry, a better quality mud cake can be formed, and the amount of mud slurry required to form the mud cake can be effectively reduced. Liu et al. [17] carried out permeation film forming experiments of different ratios of slurry in circular-gravel stratum to study the effects of slurry specific gravity, viscosity, and grouting pressure on amount of infiltrated water, film-forming time, and slurry film shape. The research found that the higher the slurry specific gravity is, the better the mud cake quality is. The higher the slurry viscosity is, the earlier the mud cake is formed and the smaller the amount of water infiltrated from slurry is. The effect of slurry specific gravity on the amount of infiltrated water is greater than that of viscosity.

In recent years, researchers have gradually adopted microview research technologies to investigate the microstructure of geomaterials, such as scanning electron microscopy (SEM), pressure pump methods (e.g., mercury intrusion porosimetry (MIP)), and computed tomography (CT) scanning technology [18]. The microstructure of a soil is mainly dependent on its composition, structural arrangement, and pore characteristics [19]. Shi et al. [20] proposed an effective SEM sample preparation method and conducted a quantitative analysis to study the pore size and shape coefficient of the soil mass. Zhang et al. [21] used SEM and CT to the microstructure of cement slurry after hydration and hardening and its influence on the macroscopic properties. Takano et al. [22] introduced CT technology to the model test of the slurry shield excavation surface. Cui et al. [23] investigated the influence of xanthan gum (XG) on slurry properties under different salty water conditions using SEM images. SEM images revealed that XG utilizes its "wrapping effect" to effectively control the slurry filtration loss. Scanning electron microscopy is widely used in the study of mud properties, but it is rarely used in the study of formation of mud cakes.

In this study, penetration tests of mud slurries are first carried out to study the change in mud filtration in different soils and identify the factors affecting the mud filtration loss. The filling form and filtration loss of various types of mud slurry filtration are summarized. Second, the microstructures of different mud filtration cakes are observed by SEM. Finally, SEM binarization images are quantitatively analyzed using fractal theory, and the relationship between fractal dimension, porosity, and mud cake formation quality is discussed.

\section{Experimental Implementation}

2.1. Experimental Materials. Silt and sand were used to simulate different soils in front of the excavated surface during large-diameter slurry shield tunneling. The soil permeability coefficient, which is related to the structure, shape, and density of soil, can effectively reflect the permeability performance of soil. Different soils were simulated by adjusting the proportion of sand and silt. The permeability coefficients of each soil are listed in Table 1 .
TABLE 1: Permeability coefficients of the soils.

\begin{tabular}{lcc}
\hline Soil & Sand proportion (\%) & Permeability coefficient $(\mathrm{cm} / \mathrm{s})$ \\
\hline$D_{1}$ & 40 & $1.18 \times 10^{-3}$ \\
$D_{2}$ & 60 & $1.60 \times 10^{-3}$ \\
$D_{3}$ & 70 & $2.15 \times 10^{-3}$ \\
\hline
\end{tabular}

The mud slurry used in this experiment was prepared by bentonite, silt with different particle sizes, sodium carboxymethyl cellulose (CMC), and water in different proportions. The montmorillonite content of the bentonite used in the experiment was $63.35 \%$. The density of the bentonite suspension was $1.01 \mathrm{~g} / \mathrm{cm}^{3}$, and the bentonite content was $9.2 \%$. Silt sand particles were screened by vibrating screen into three different particle groups, and the particle size range is $<75 \mu \mathrm{m}, 75 \mu \mathrm{m} \sim 100 \mu \mathrm{m}$, and $100 \mu \mathrm{m} \sim 150 \mu \mathrm{m}$. The specific gravity and particle size of mud slurries can be effectively adjusted by adding silt and sand with different particle sizes in the process of mud preparation. Sodium hydroxymethyl cellulose is a highmolecular polymer. In the experiment, carboxymethyl cellulose was configured as a $2 \%$ concentration solution in $50^{\circ}$ water. The characteristics of the mud slurries used in the experiments are summarized in Table 2.

2.2. Experimental Apparatus and Test Method. To simulate the penetration of mud slurries in different soils, a penetration device was designed and fabricated. The device is composed of an air pressure supply pump, slurry penetration column, and data acquisition system, as shown in Figure 1. In the tests, an automatic pressure pump was used to provide air pressure; the pump can act directly on the mud surface and provide a maximum pressure of $600 \mathrm{kPa}$. The column has a diameter of $22 \mathrm{~cm}$. The filtration volume of mud slurry is measured using a measuring cylinder. The microstructure of the soil before and after mud slurry penetration was investigated using a KYKY-6200 scanning electron microscope as depicted in Figure 2. The scanning electron microscopy consists of two parts: the lens part and the circuit part. The instrument has a resolution of $4.5 \mathrm{~nm}$, maximum allowable sample diameter of $50 \mathrm{~nm}$, amplification factor of $15-250,000$, and acceleration voltages of $0-30 \mathrm{kV}$. Due to the low conductivity of soil, it is difficult to observe directly, and it is easy to cause electrostatic interference, which affects the observation quality. The mud filtration cake samples used for scanning electron microscopy need to be processed by the SBC-12 ion sputtering device shown in Figure 3 . The mud filtration cake samples after being treated had perfect electrical conductivity.

Nine groups of mud slurries penetrated three different soils under graded pressures of 50,100,150, 200, 250, and $300 \mathrm{kPa}$ (this pressure is the difference between mud slurry pressure and groundwater pressure, that is, the effective working surface support pressure). The pressure was increased once stable penetration was achieved. The test procedure was as follows: 
TABLE 2: Characteristics of the mud slurries.

\begin{tabular}{lcccc}
\hline Mud slurry & Bentonite-to-water ratio & Grain diameter $(\mathrm{mm})$ & CMC content $(\mathrm{g} / \mathrm{L})$ & Specific gravity \\
\hline$S_{1}$ & $150: 1000$ & $<0.15$ & 1.5 & 1.1 \\
$S_{2}$ & $150: 1000$ & $<0.1$ & 2.5 & 1.2 \\
$S_{3}$ & $150: 1000$ & $<0.075$ & 2 & 1.3 \\
$S_{4}$ & $125: 1000$ & $<0.15$ & 2.5 & 1.3 \\
$S_{5}$ & $125: 1000$ & $<0.1$ & 1.5 & 1.1 \\
$S_{6}$ & $125: 1000$ & $<0.075$ & 2.5 & 1.2 \\
$S_{7}$ & $100: 1000$ & $<0.15$ & 1.5 & 1.2 \\
$S_{8}$ & $100: 1000$ & $<0.1$ & 2 & 1.3 \\
$S_{9}$ & $100: 1000$ & $<0.075$ & & 1.1 \\
\hline
\end{tabular}

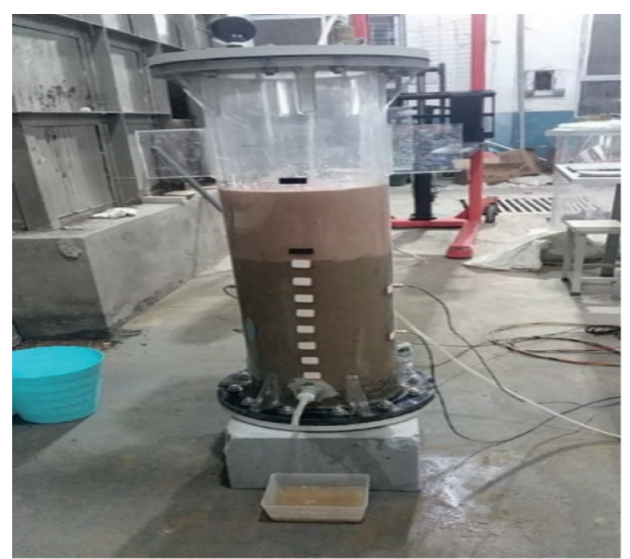

(a)

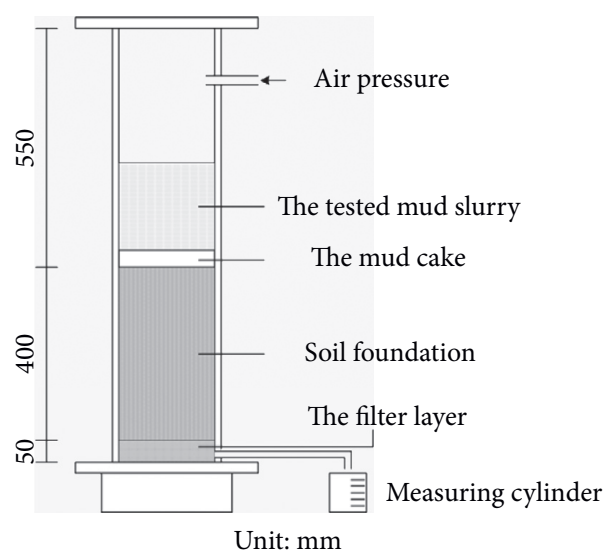

(b)

FIgURE 1: Penetration device designed to simulate the penetration of mud slurry in soil.

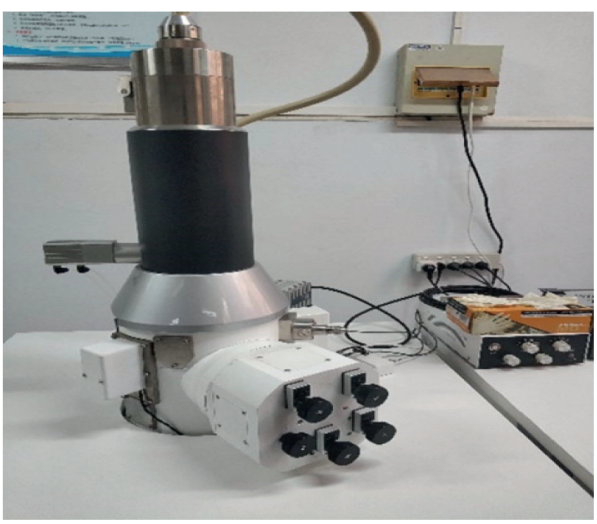

FIGURE 2: KYKY-6200 scanning electron microscopy setup.

(1) A working condition (such as $S_{1} D_{1}$ ) is selected to configure the characteristics of the mud slurry. The appropriate soil sample is placed in the penetration device, and the soil is vibrated and tamped after each $5 \mathrm{~cm}$ addition to achieve a total soil thickness of $40 \mathrm{~cm}$.

(2) A cylindrical sample with a diameter of $10 \mathrm{~mm}$ and thickness of $10 \mathrm{~mm}$ is removed from the surface of the soil for SEM analysis. The remaining soil sample is used to flatten the surface, and the soil is saturated with water through a water valve at the bottom of the column. After water inundates the soil surface, water injection is stopped, and the soil is allowed to

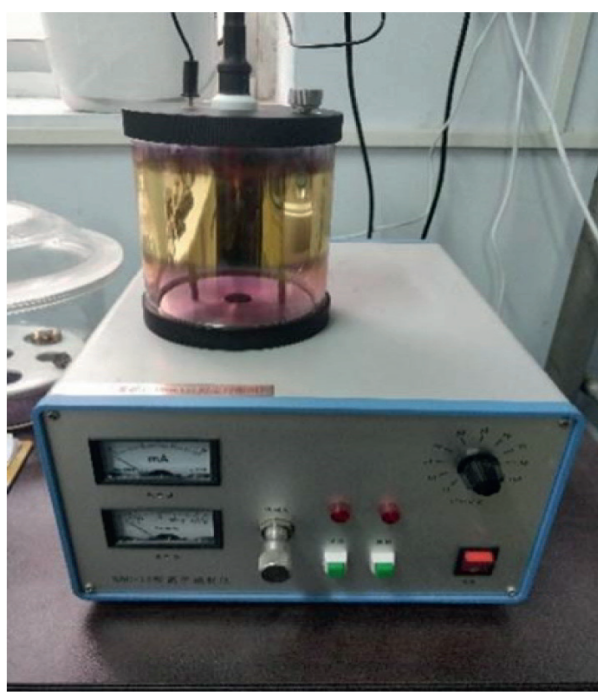

Figure 3: SBC-12 ion sputtering device.

become fully saturated by standing for $24 \mathrm{~h}$, after which the excess water is released.

(3) Stone is placed above the soil to reduce the impact of water flow through the soil. Permeability tests of the soil are carried out under a constant water head, and the displacement data are recorded. Then, the excess water in the upper part of the soil is discharged, and the stone is removed. 
(4) The surface is filled with sifted soil, and the prepared mud slurry is added to the penetration device slowly, controlling the height of mud slurry to $20 \mathrm{~cm}$. Pressure is applied stepwise from the upper end to the silo with an initial pressure of $50 \mathrm{kPa}$. Meanwhile, the displacement changes during the penetration process are recorded. After the filtration loss becomes stable, the pressure is increased in increments of $50 \mathrm{kPa}$ until the limit pressure of $300 \mathrm{kPa}$ is reached.

(5) The exhaust valve is discharged slowly after unloading, and the mud particles in the stratigraphic filling form are observed.

(6) Mud filtration cake samples of $10 \mathrm{~mm} \times 10 \mathrm{~mm} \times$ $10 \mathrm{~mm}$ are prepared after the penetration tests for three types of soil foundation and placed into a hightemperature dryer to dry.

(7) The dried mud filtration cake samples are fixed on the platform with a conductive adhesive and placed into the SBC-12 ion sputtering device to measure the conductivity of the samples. The treated samples are then observed by SEM.

The filtration loss generated under the pressure of the first stage is taken as the mud filtration loss required for the formation of a mud filtration cake. Once stable penetration is achieved under the pressure of the first stage, a mud filtration cake is formed.

\section{Experimental Results}

3.1. Change in the Filtration Loss of Mud Slurry. With the initial application of mud pressure, the filtration loss of mud slurry increases rapidly. Then, as mud particles fill in the pores of the soil, the permeability coefficient of the soil decreases, and the filtration loss of mud slurry decreases gradually. When the filtration loss is basically unchanged, the mud slurry reaches the stage of seepage stabilization, and the corresponding time is the mud stabilization time. Because the seepage flow rate is measured at intervals of $20 \mathrm{~s}$ during the test, the mud stabilization time obtained directly from the cumulative curve will have a large error. Thus, the mud stabilization time is determined only according to the filtration loss of mud slurry under the first pressure stage.

The cumulative curves of filtration losses of mud slurries in soil $D_{1}$ are shown in Figure 4(a). In soil $D_{1}$, the final cumulative filtration losses of mud slurries $S_{2}$ and $S_{6}$ were $956.9 \mathrm{~mL}$ and $1033.6 \mathrm{~mL}$, respectively. The filtration losses of mud slurries increased significantly under the multistage pressure. As the pressure increased, the difference in the filtration loss of mud slurry between two adjacent stages decreased gradually. The stabilization time of the mud penetration was approximately $100 \mathrm{~s}$. The filtration loss of mud slurry $S_{9}$ was less than that of $S_{2}$ and $S_{6}$ but significantly greater than that of the other six slurries. The stabilization time of the mud penetration was approximately $60 \mathrm{~s}$. The other six slurries exhibited relatively small mud filtration losses, with cumulative filtration losses of less than $600 \mathrm{~mL}$. The mud stabilization times were relatively short, and stable penetration was achieved in $40 \mathrm{~s}$.
Figure 4(b) shows the cumulative curves of filtration losses of mud slurries in soil $D_{2}$. In soil $D_{2}$, mud slurry $S_{7}$ exhibited the greatest filtration loss, with a final cumulative filtration loss of $1026 \mathrm{~mL}$. The stabilization time of mud $S_{7}$ penetration was approximately $140 \mathrm{~s}$. The filtration losses of mud slurries $S_{2}, S_{4}$, and $S_{6}$ were greater than those of the other five slurries. The stabilization time of the mud was approximately $60 \mathrm{~s}$. The filtration losses of the other five mud slurries were relatively small, with cumulative filtration losses of less than $600 \mathrm{~mL}$. Moreover, mud slurry infiltration stability was achieved within $20 \mathrm{~s}$. The cumulative curves of filtration losses of mud in soil $D_{3}$ are shown in Figure 4(c). In soil $D_{3}$, the filtration loss of mud slurry $S_{7}$ was the greatest, and the final cumulative filtration loss was $883 \mathrm{~mL}$. The stabilization time of the mud slurry penetration was approximately $100 \mathrm{~s}$. The filtration losses of mud slurries $S_{1}, S_{6}$, $S_{8}$, and $S_{9}$ were significantly greater than those of the other four slurries, and the mud stabilized within 40-60 s. The other four mud slurries exhibited small filtration losses in the process of infiltration, and the cumulative filtration losses were less than $500 \mathrm{~mL}$. Meanwhile, all of the slurries reached stable infiltration within $20 \mathrm{~s}$.

To sum up, as the initial pressure was applied, the filtration loss of mud slurry increased sharply. In the subsequent loading process, the filtration loss continued to increase, the growth rate slowed down significantly, and the growth rate was much slower than the initial loading stage. Observing the filtration loss changes of 9 groups of mud slurry in three soils, it is found that the slurry filtration loss changes of mud slurry can be divided into three categories. In the first category, the filtration loss of mud slurry is relatively large and it takes a long time to reach stability, about $100 \mathrm{~s}$, and a filtration loss can still be formed under the action of $300 \mathrm{kPa}$. In the second category, the filtration loss of mud slurry is significantly smaller than that in the first category. The mud stabilization time is about $60 \mathrm{~s}$, and stable penetration can still be formed at $300 \mathrm{kPa}$. In the third category, the filtration loss of the mud slurry is less than $600 \mathrm{ml}$, and stable penetration can be achieved within $40 \mathrm{~s}$.

3.2. Filling Morphology of the Slurry Particles. The penetration tests for soils $D_{1}, D_{2}$, and $D_{3}$ show that the filling forms of the mud slurry particles can be divided into three types in this study. The first type is the mud filtration cake, as shown in Figure 5(a). All particles of the mud are blocked on the soil surface, forming a thick mud cake. The filtration loss of the mud slurry is small under a pressure of $50 \mathrm{kPa}$, and it does not change after applying increasing pressure levels. The filtration water is clear. This indicates that almost all of the mud slurry particles have filled and blocked the surface of the formation to form a relatively compact particle layer with a clear boundary. After water loss and consolidation, the mud filtration cake is separated from the soil. For example, mud slurries $S_{1}, S_{3}, S_{4}, S_{5}, S_{7}$, and $S_{8}$ penetrating soil $D_{1}$; mud slurries $S_{1}, S_{3}, S_{5}, S_{8}$, and $S_{9}$ penetrating soil $D_{2}$; and mud slurries $S_{1}, S_{2}, S_{3}, S_{4}, S_{5}$, and $S_{9}$ penetrating soil $D_{3}$ form mud filtration cakes. 


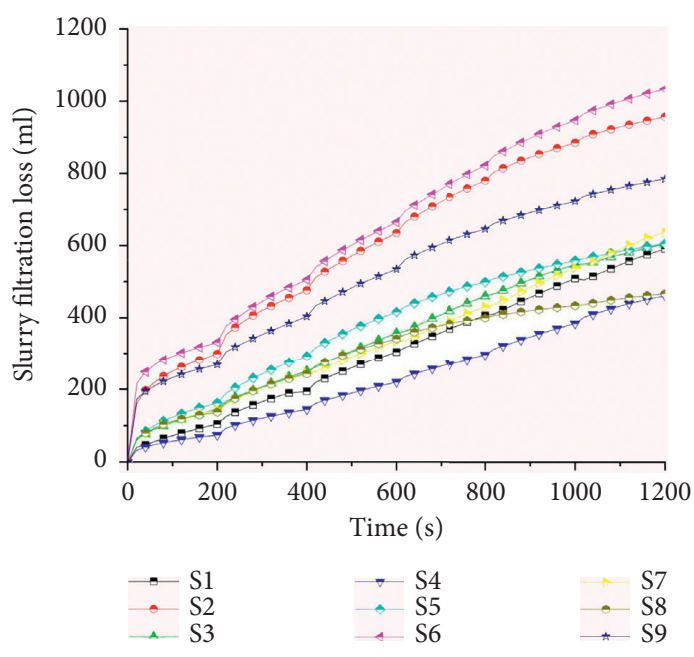

(a)

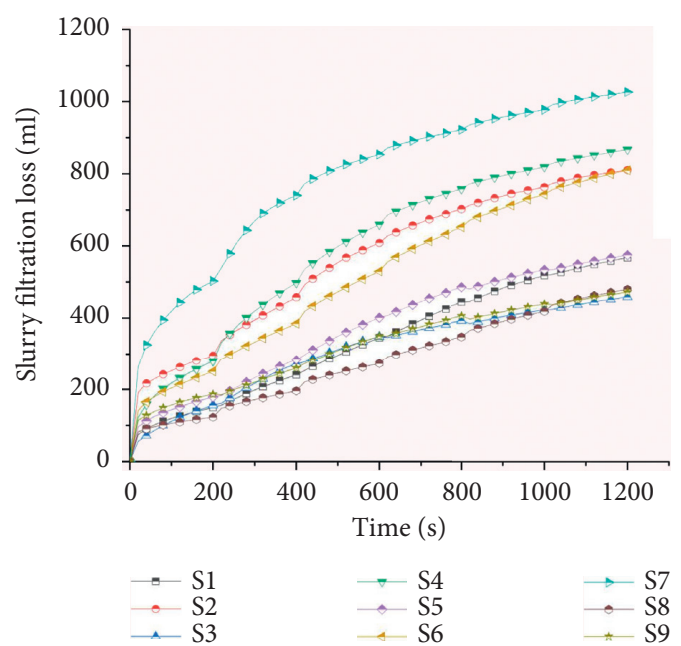

(b)

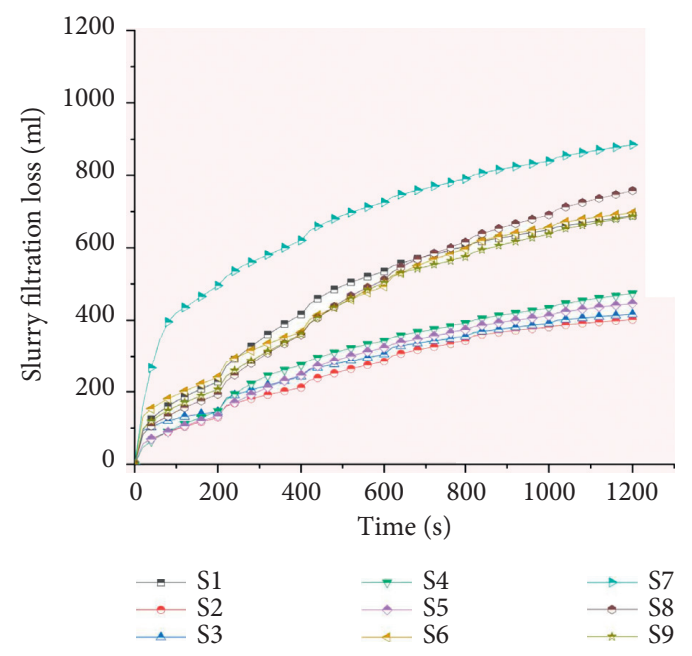

(c)

FIgURE 4: Cumulative curves of filtration losses of mud slurries in (a) soil $D_{1}$, (b) soil $D_{2}$, and (c) soil $D_{3}$.

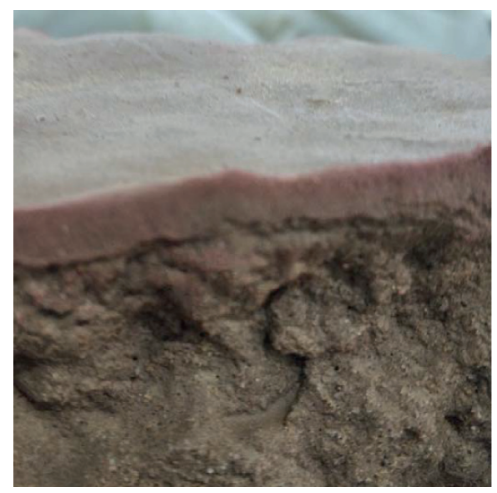

(a)

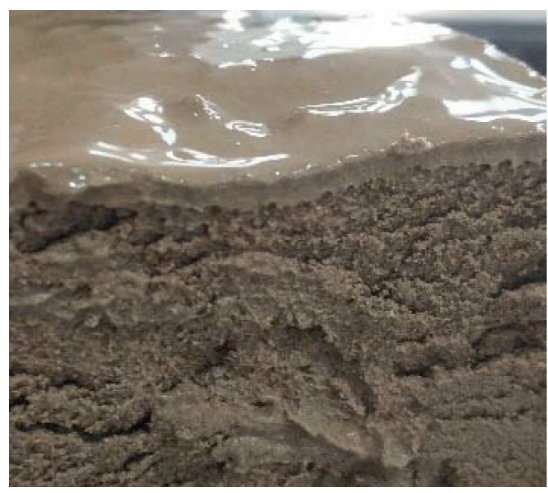

(b)

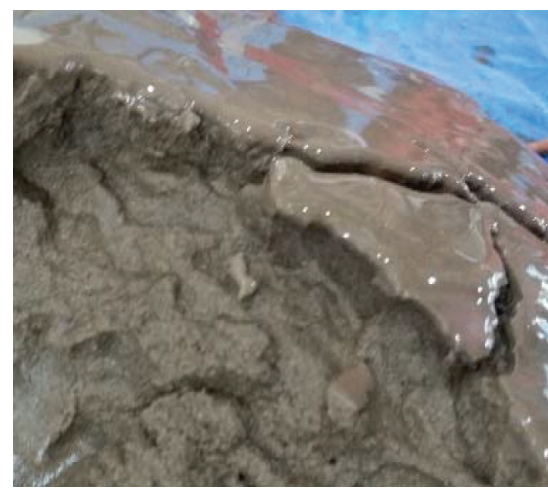

(c)

FIGURE 5: Categories of filling forms for mud slurries permeating the soils. (a) Mud filtration cake. (b) Mud cake + permeation zone. (c) Permeation zone.

The second type is the mud filtration cake + permeation zone, as shown in Figure 5(b). A small amount of mud slurry particles accumulated on the surface of the soil to form a thin mud cake. Under a pressure of $50 \mathrm{kPa}$, the mud slurry produces a large filtration loss, which rapidly decreases and stabilizes. With increasing pressure, the filtration loss 
fluctuates slightly and then rapidly stabilizes with clear filtration water. This indicates that the mud slurry particles remain in the soil without passing through to form a permeable zone with a particle layer on the surface of the soil. The particle layer cannot be easily separated from the soil. For example, mud slurries $S_{2}$ and $S_{9}$ penetrating soil $D_{1}$; mud slurries $S_{2}, S_{4}$, and $S_{6}$ penetrating soil $D_{2}$; and mud slurries $S_{6}$ and $S_{8}$ penetrating soil $D_{3}$ form a mud filtration cake + permeation zone.

The third category is the permeation zone, as shown in Figure 5(c). A large amount of mud slurry particles penetrated into the soil without forming an effective mud cake. After the first pressure stage is applied, the mud slurry produces a large filtration loss, which cannot reach a stable state within a short time. With increasing pressure, the filtration loss increases rapidly, and the filtration water becomes muddy. Because soils with strong permeabilities are not used in the tests, the mud slurry is not completely filtered out by the soil. No particles are present on the surface of soil at the end of the test. For example, mud slurry $S_{6}$ penetrating soil $D_{1}$ and mud slurry $S_{7}$ penetrating soils $D_{2}$ and $D_{3}$ form permeation zones.

3.3. SEM Images of the Mud Filtration Cake. The mud filtration cakes obtained from the penetration tests with nine groups of mud slurries in soils $D_{1}, D_{2}$, and $D_{3}$ were observed by SEM. The samples were amplified 1000 times, and the SEM images were enhanced and sharpened. SEM shows that the particles in the original soil are relatively loose, with different particle sizes and larger pore sizes. After the mud slurry penetration, the mud slurry particles accumulate on the surface of the soil, forming a mud filtration cake, and the porosity decreases. The pores in the first type of the mud filtration cakes are completely blocked, and the pores in the second type are filled with small mud slurry particles and then form a particle layer with low permeability; finally, the particles in the third type cannot plug the soil pores. The microscopic morphology observed by SEM is consistent with the particle filling morphology observed macroscopically.

In the quantitative analysis of SEM images, black and white grayscales are usually selected for processing, with black representing pores and white representing particles. The threshold value was calculated by the maximum class square error method for the mud filtration cake samples. The original and binary images of samples $D_{1}, S_{1} D_{1}, S_{2} D_{2}$, and $S_{7} D_{3}$ were obtained, with threshold values of 93, 61, 48, and 104, respectively. The areas with gray values less than the threshold were defined as 0 , while the areas greater than the threshold were defined as 255. As shown in Figures 6-9, after binarization of the SEM images, the black parts of the images represent the pores, and their sizes and shapes are consistent with the original SEM images. This confirms that the binarization effect was good and the threshold selection was reasonable.

\section{Discussion}

4.1. Filtration Loss and Filling Morphology of the Slurry Particles. By observing the slurry filtration loss of each group in the soil, it can be found that when the filtration loss is large after permeation, the formation cannot form an effective mud filtration cake but can form a permeation zone. If the filtration loss is small, a good-quality mud filtration cake can be formed. This is related to the transportation of mud slurry particles. The mud particles block the soil pores, and the subsequent particles cannot enter the pores, so they accumulate on the surface of the soil and form mud filtration cake. The formation of mud filtration cake reduces the permeability, and the more effective the formation of mud cake is, the smaller the filtration loss is. Therefore, the mud filtration loss can effectively reflect the quality of mud filtration cake.

4.2. Influencing Factors of Filtration Loss. There are many factors that affect filtration loss, and mud slurry material is a very important factor. To investigate the influence of the mud slurry composition on the mud filtration loss and quality of the mud filtration cake, an orthogonal experimental design was used for the mud proportions. Four influencing factors were selected in these experiments: the bentonite-to-water ratio, grain diameter, carboxymethyl cellulose content, and specific gravity of the slurry. The size of the particle size can affect the penetration of the mud in the soil. The particle size is large, the mud will not easily permeate through the soil and is more likely to block the soil. CMC content can increase the viscosity of the mud slurry. Specific gravity is also an important index of mud slurry. All four of these factors can affect the mud slurry penetrating the soil and thus the filtration loss.

According to the results of the permeability tests of mud slurry in soil $D_{1}$, the filtration loss of mud slurry under the first stage pressure was taken as the reference value, influencing factors were selected, range analyses of the orthogonal tests were carried out, and the relationships between the filtration loss of mud slurry and various factors during the formation of the mud filtration cake were obtained, as shown in Figure 10(a).

The results in Figure 10(b) show that the influence of mud slurry composition parameters on the filtration loss of mud slurry was in the following order: specific gravity $>$ grain diameter $>$ CMC content $>$ bentonite-to-water ratio. The factors having the greatest influence on the filtration loss in the formation of the mud filtration cake were the mud grain diameter and mud slurry specific gravity. When the mud slurry specific gravity was less than 1.2 , the filtration loss of mud slurry was directly proportional to the specific gravity; when the specific gravity was greater than 1.2, the filtration loss of mud slurry was inversely proportional to the specific gravity. When the particle size of the mud slurry was less than $0.15 \mathrm{~mm}$, the filtration loss decreased significantly with increasing particle size.

The relationships between the filtration loss of mud slurry and the influencing factors during the formation of the mud filtration cake are shown in Figure 10(c). It can be seen that the influence of the mud slurry composition on the mud slurry filtration loss in soil $D_{2}$ is consistent with that in soil $D_{1}$. 

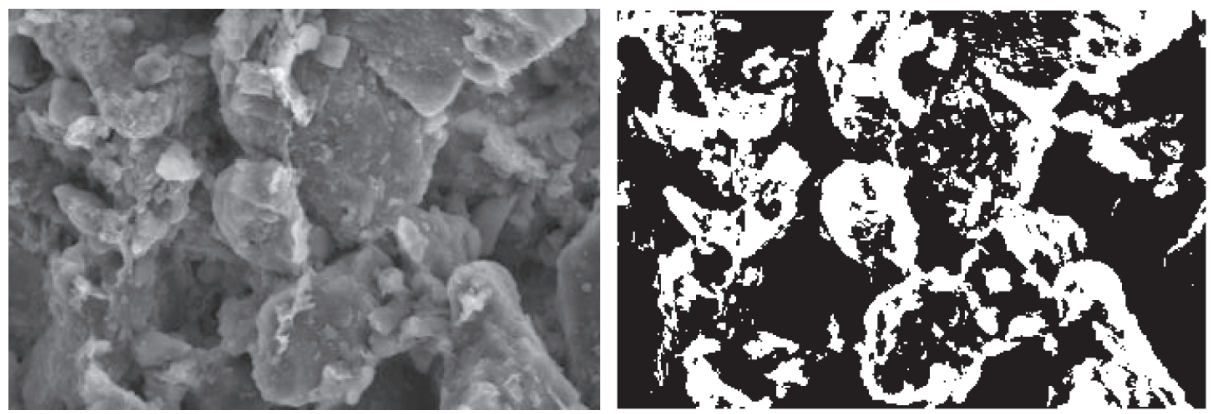

Figure 6: SEM images of soil $D_{1}$ before and after binarization.
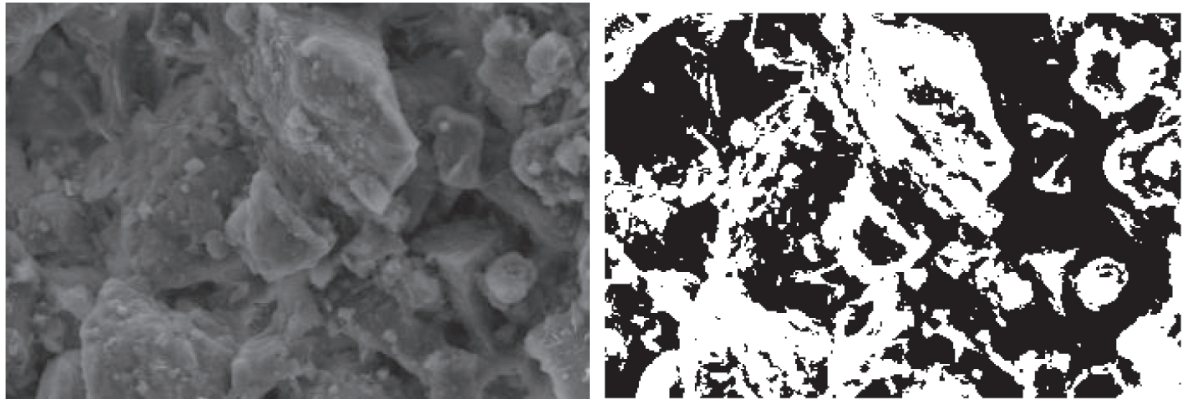

FIGURE 7: SEM images of sample $S_{1} D_{1}$ before and after binarization (mud filtration cake).
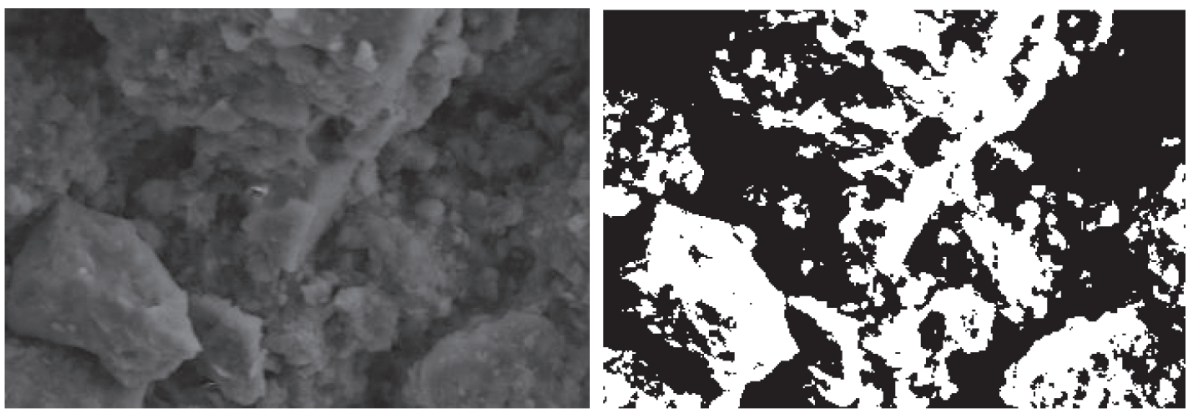

Figure 8: SEM images of sample $S_{2} D_{2}$ before and after binarization (mud cake + permeation zone).
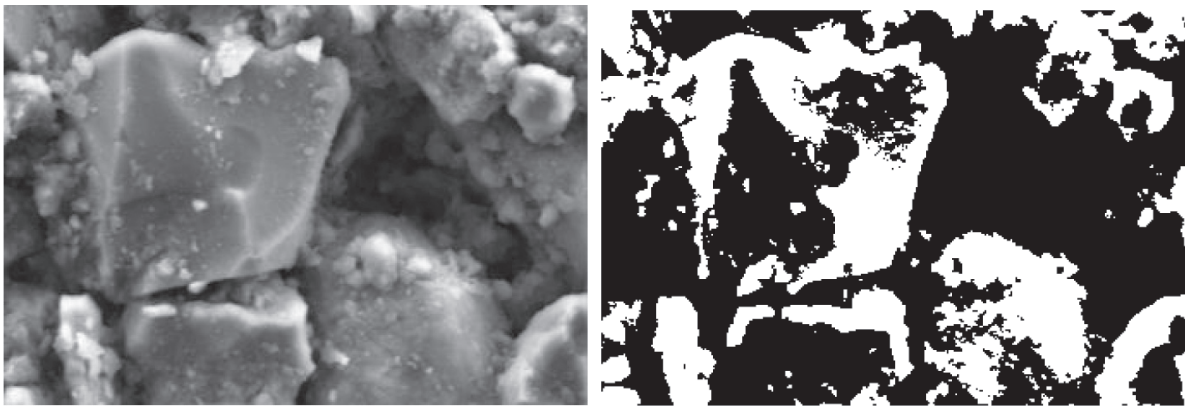

Figure 9: SEM images of sample $S_{7} D_{3}$ before and after binarization (permeation zone).

It can be seen in Figure 10(c) that the correlations between the mud slurry composition and the filtration loss of mud slurry occur in the order of grain diameter $>$ bentoniteto-water ratio $>$ specific gravity $>\mathrm{CMC}$ content. The main factor affecting the filtration loss of mud slurry during the formation of the mud filtration cake was the mud grain diameter. However, the effect of the mud grain diameter was not significantly different from that of the other three 


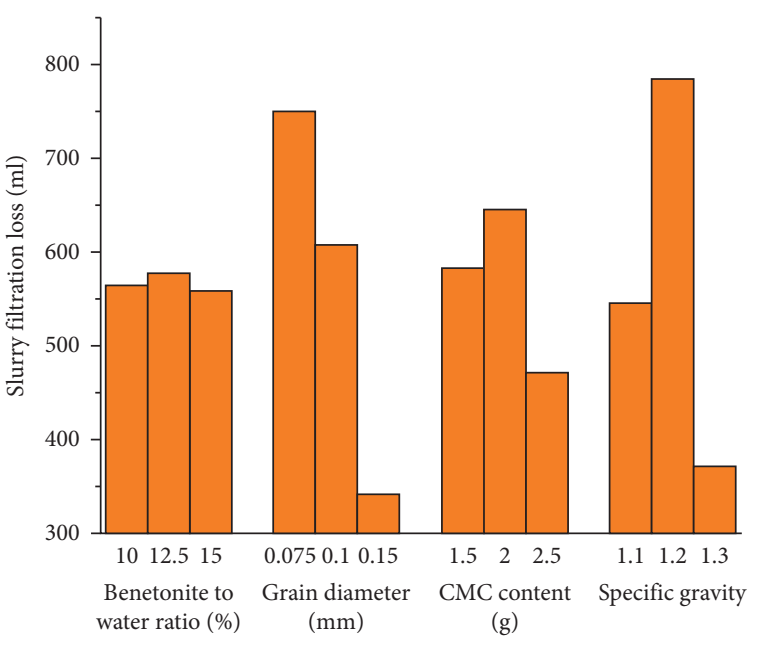

(a)

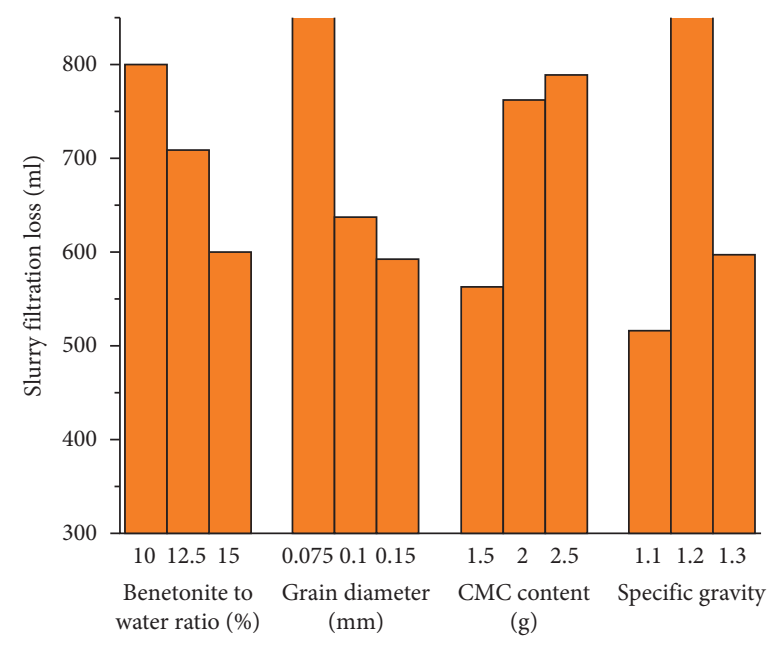

(b)

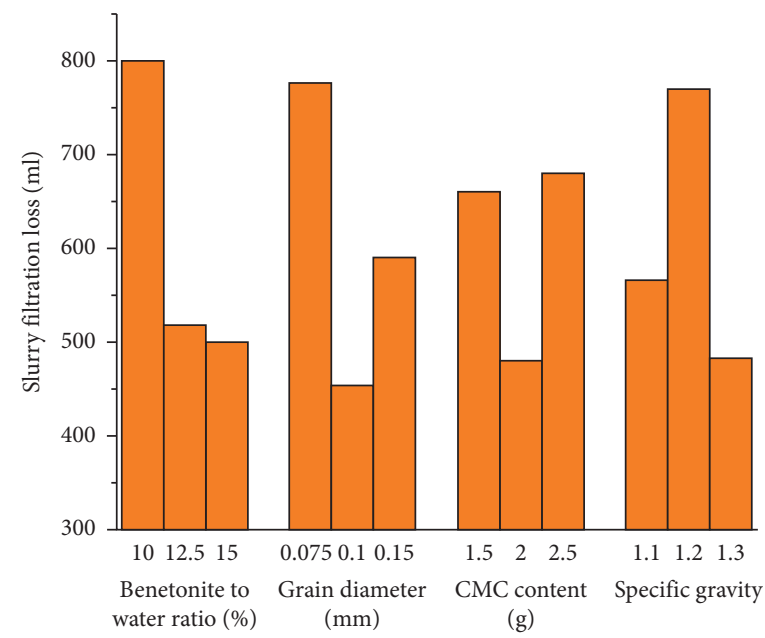

(c)

FIGURE 10: Relationships between the mud slurry composition and filtration loss. (a) Soil $D_{1}$. (b) Soil $D_{2}$. (c) Soil $D_{3}$.

factors. When the grain diameter was less than $0.1 \mathrm{~mm}$, the filtration loss of mud slurry decreased significantly with increasing grain diameter. When the grain diameter was larger than $0.1 \mathrm{~mm}$, the filtration loss of mud slurry increased with increasing grain diameter. Thus, there was an optimal grain diameter to minimize the filtration loss of mud slurry.

4.3. Porosity and Fractal Dimension of Mud Filtration Cake. After binarization of the original SEM image, the pores and particles in the image are distinguished. The porosity, $\Phi$, can be obtained with the following equation:

$$
\phi=\sum_{i=0}^{T-1} \frac{N_{i}}{N}=\frac{S_{0}}{S_{1}}
$$

where $i$ is the gray value, $T$ is the threshold value, $N_{i}$ is the number of pixels with a gray value of $i, N$ is the total number of pixels, $S_{0}$ is the pore area, and $S_{1}$ is the particle area.

The porosities of the 27 samples of mud filtration cake were calculated using equation (1), and the results are given in Table 3.
It can be seen from Table 3 that $S_{6} D_{1}, S_{7} D_{2}$, and $S_{7} D_{3}$ have the greatest two-dimensional porosities. This indicates that the particles cannot plug the soil after mud slurry penetration because the pores are large, and thus good water permeability is obtained. The small two-dimensional porosities of the other groups indicate that a more effective mud filtration cake is formed on the surface of the soil with poor permeability, such as in samples $S_{1} D_{1}, S_{3} D_{1}$, and $S_{8} D_{2}$.

By observing the porosity of the samples, it is found that when the porosity of the samples is large, most of them cannot form effective mud filtration cake but can form permeation zones, such as $S_{6} D_{1}, S_{7} D_{2}$, and $S_{7} D_{3}$. Samples with low porosity can form effective mud filtration cake, such as $S_{1} D_{1}, S_{3} D_{1}, S_{8} D_{2}$, and so on. However, some samples with large porosity, such as $S_{1} D_{2}$ and $S_{5} D_{3}$, formed goodquality mud filtration cake. It shows that it is not feasible to judge the quality of mud cake by the size of porosity.

Recent studies have indicated that the microstructures of geomaterials such as soil or rock have self-similar characteristics $[24,25]$. The fractal theory is an effective method to describe the microstructure characteristics of rocks and soils 
Table 3: Two-dimensional porosities of 27 samples of mud filtration cake.

\begin{tabular}{lccccccrrr}
\hline Number & $S_{1}$ & $S_{2}$ & $S_{3}$ & $S_{4}$ & $S_{5}$ & $S_{6}$ & $S_{7}$ & $S_{8}$ & $S_{9}$ \\
\hline$D_{1}$ & 0.431 & 0.549 & 0.400 & 0.451 & 0.482 & 0.618 & 0.487 & 0.538 & 0.519 \\
$D_{2}$ & 0.500 & 0.502 & 0.459 & 0.497 & 0.458 & 0.520 & 0.645 & 0.397 & 0.491 \\
$D_{3}$ & 0.496 & 0.467 & 0.428 & 0.428 & 0.519 & 0.530 & 0.665 & 0.542 & 0.493 \\
\hline
\end{tabular}

TABle 4: Fractal dimensions for pore area in 27 samples of mud filtration cake.

\begin{tabular}{lccccccccc}
\hline Number & $S_{1}$ & $S_{2}$ & $S_{3}$ & $S_{4}$ & $S_{5}$ & $S_{6}$ & $S_{7}$ & $S_{8}$ & $S_{9}$ \\
\hline$D_{1}$ & 1.813 & 1.886 & 1.841 & 1.817 & 1.847 & 1.893 & 1.842 & 1.848 \\
$D_{2}$ & 1.828 & 1.87 & 1.83 & 1.859 & 1.821 & 1.871 & 1.903 & 1.809 & 1.867 \\
$D_{3}$ & 1.851 & 1.837 & 1.826 & 1.841 & 1.844 & 1.873 & 1.897 & 1.858 & 1.857 \\
\hline
\end{tabular}

[26]. The fractal dimensions of the pore area in the 27 samples of mud filtration cake were analyzed using the differential box-counting method [27].

The fractal dimensions of the pore area in the 27 samples of mud filtration cake are given in Table 4. The fractal dimensions of the pore area distributions in the 27 samples are between 1.80 and 1.91, which indicates that the pores of the mud filtration cakes have a fractal distribution. Sample $S_{7} D_{2}$ had the greatest fractal dimension. The mud particle accumulation type of $S_{7} D_{2}$ was a mud filtration cake; almost all of the mud particles fill and block the surface of soil $D_{2}$, and the pore structure of the $S_{7} D_{2}$ mud cake observed in the SEM image is irregular. Sample $S_{8} D_{2}$ has the smallest fractal dimension, and the pore structure of the $S_{8} D_{2}$ mud filtration cake is regular. This indicates that the regularity of the pore structure has a significant influence on the fractal dimension.

By observing the fractal dimension and particle filling type of the sample, it is found that when the fractal dimension is less than 1.859, the particle filling form is mud filtration cake. When the fractal dimension is greater than 1.859 and less than 1.893, the filling form of particles is mud cake + permeation zone. When the fractal dimension is greater than 1.893 , the particle filling form is a permeation zone. So, the fractal dimension can be used as an important index to evaluate the quality of the formed mud filtration cake.

\section{Conclusion}

Penetration tests with soils $D_{1}, D_{2}$, and $D_{3}$ show that three forms of particle accumulation occur when mud slurries penetrate the soil: mud filtration cake, mud cake + permeation zone, and permeation zone. Correspondingly, three types of mud filtration loss also occur: low filtration loss with short stabilization time, high filtration loss with long stabilization time, and unstable filtration loss. The type of mud filtration cake formed can be determined based on the change in the filtration loss.

The filtration loss of mud slurry at the first applied pressure stage is recognized as the necessary filtration loss for the formation of a mud filtration cake. The specific gravity and grain diameter are the most significant factors affecting the filtration loss of mud slurry during mud slurry penetration of the soil.

The fractal dimension of pore area in mud filtration cake is beneficial to classify the type of mud filtration cake. For fractal dimension $<1.859$, an effective mud cake can be formed. For $1.859<$ fractal dimension <1.893, a mud cake + permeation zone can be formed. For fractal dimension $>1.893$, a permeation zone can be observed.

\section{Data Availability}

The data used to support the finding of this study are included within the article.

\section{Conflicts of Interest}

The authors declare that they have no conflicts of interest regarding the publication of this paper.

\section{Acknowledgments}

This study was supported by the National Natural Science Foundation of China (grant no. 51708512).

\section{References}

[1] H. Cheng, J. Chen, and G. Chen, "Analysis of ground surface settlement induced by a large EPB shield tunnelling: a case study in Beijing, China," Environmental Earth Sciences, vol. 78, no. 20, p. 605, 2019.

[2] X. M. Xiao, Y. M. Xia, X. T. Mao et al., "Effect of the nozzle structure of the large-diameter slurry shield cutterhead on the scouring characteristics," Journal of the Brazilian Society of Mechanical Sciences and Engineering, vol. 42, no. 4, pp. 10-24, 2020.

[3] C. P. Zhang, Y. Cai, and W. J. Zhu, "Numerical study and field monitoring of the ground deformation induced by large slurry shield tunnelling in sandy cobble ground," Advances in Civil Engineering, vol. 2019, Article ID 4145721, 2019.

[4] P. Fritz, "Additives for slurry shields in highly permeable ground," Rock Mechanics and Rock Engineering, vol. 40, no. 1, pp. 81-95, 2007.

[5] T. Xu and A. Bezuijen, "Bentonite slurry infiltration into sand: filter cake formation under various conditions," Géotechnique, vol. 69, no. 12, pp. 1095-1106, 2019.

[6] S. H. Kim and F. Tonon, "Face stability and required support pressure for TBM driven tunnels with ideal face membrane-drained case," Tunnelling and Underground Space Technology, vol. 25, no. 5, pp. 526-542, 2010.

[7] Y.-M. Ryu, Y.-S. Kwon, T.-H. Kim, and I.-M. Lee, "Slurry clogging criteria for slurry shield tunnelling in highly 
permeable ground," KSCE Journal of Civil Engineering, vol. 23, no. 6, pp. 2784-2793, 2019.

[8] T. Watanabe and H. Yamazaki, "Giant size slurry shield is a success in Tokyo," Tunnels and Tunnelling, vol. 13, no. 1-2, pp. 13-17, 1981.

[9] Z. Yang, J. Chen, Z. C. Sun, Y. F. You, J. J. Zhou, and Q. Lu, "Study on improved test of seawater slurry for slurry shield," Rock and Soil Mechanics, vol. 41, 2020.

[10] P. Wei, X. D. Ni, and T. K. Li, "Preliminary study on formation law simulation of filter-cake in slurry shield at mesoscale level," Applied Mechanics and Materials, vol. 224, pp. 362-366, 2012.

[11] A. M. Talmon, D. R. Mastbergen, and M. Huisman, "Invasion of pressurized clay suspensions into granular soil," Journal of Porous Media, vol. 16, no. 4, pp. 351-365, 2013.

[12] F. Min, W. Zhu, and X. Han, "Filter cake formation for slurry shield tunneling in highly permeable sand," Tunnelling and Underground Space Technology, vol. 38, pp. 423-430, 2013.

[13] D. Wu, S. H. Zhou, and X. Wen, "Laboratory test and application of filter cake formation in sand during slurry shield construction," Chinese Journal of Rock Mechanics and Engineering, vol. 34, pp. 3460-3467, 2015.

[14] F. L. Min, W. Zhu, X. R. Han, and X. C. Zhong, "The effect of clay content on filter-cake formation in highly permeable gravel," in Proceedings of the 2010 GeoShanghai International Conference, pp. 210-215, Shanghai, China, May 2010.

[15] W. T. Ye, J. Y. Wang, L. L. Fu et al., "Laboratory test and characteristic of filter film formation of slurry shield in medium-coarse sand stratum in Fuzhou," Chinese Journal of Rock Mechanics and Engineering, vol. 37, no. 5, pp. 1260-1269, 2018.

[16] H. Wang, J. Chen, H. Liu et al., "Study on the influence of mud properties on the stability of excavated face of slurry shield and the quality of filter cake formation," Journal of Marine Science and Engineering, vol. 8, no. 4, p. 291, 2020.

[17] D. S. Liu, X. R. Liu, C. Q. Lin et al., "Experimental study and engineering application of slurry permeability mechanism of slurry shield in circular-gravel stratum," Arabian Journal of Geosciences, vol. 13, no. 19, pp. 1-12, 2020.

[18] J. Zhang, S. Li, Z. Li, C. Liu, and Y. Gao, "Feasibility study of red mud for geopolymer preparation: effect of particle size fraction," Journal of Material Cycles and Waste Management, vol. 22, no. 5, pp. 1328-1338, 2020.

[19] B. Xiong, M. Skitmore, and B. Xia, "A critical review of structural equation modeling applications in construction research," Automation in Construction, vol. 49, pp. 59-70, 2015.

[20] B. Shi, Z. Wu, H. Inyang, J. Chen, and B. Wang, "Preparation of soil specimens for SEM analysis using freeze-cut-drying," Bulletin of Engineering Geology and the Environment, vol. 58, no. 1, pp. 1-7, 1999.

[21] D. Zhang, F. Sun, and T. Liu, "Study on preparation of coal gangue-based geopolymer concrete and mechanical properties," Advances in Civil Engineering, vol. 2021, Article ID 5117584, 13 pages, 2021.

[22] D. Takano, J. Otani, H. Nagatani, and T. Mukunoki, “Application of $\mathrm{x}$-ray $\mathrm{CT}$ on boundary value problems in geotechnical engineering: research on tunnel face failure," in Proceedings of the GeoCongress 2006: Geotechnical Engineering in the Information Technology Age, pp. 1-6, Atlanta, GA, USA, 2006.

[23] W. Cui, D. Liu, H. F. Song, S. R. Zhang, and S. W. He, "Experimental study of salt-resisting slurry for undersea shield tunnelling," Tunnelling and Underground Space Technology, vol. 98, 2020.

[24] X. M. Huang, J. W. Sun, C. Y. Shi, Y. Du, and G. L. Xu, "Fractal analysis of the penetration flow through micro-nano porous gaskets with effects of slippage and stress-sensitivity," Fractals, vol. 27, no. 3, 2019.

[25] G. L. Sheng, Y. L. Su, W. D. Wang, F. Javadpour, and M. R. Tang, "Application of fractal geometry in evaluation of effective stimulated reservoir volume in shale gas reservoirs," Fractals, vol. 25, no. 4, 2017.

[26] T. Miao, B. Yu, Y. Duan, and Q. Fang, "A fractal analysis of permeability for fractured rocks," International Journal of Heat and Mass Transfer, vol. 81, pp. 75-80, 2015.

[27] L. Zhang, F. Dang, W. Ding, and L. Zhu, "Quantitative study of meso-damage process on concrete by CT technology and improved differential box counting method," Measurement, vol. 160, Article ID 107832, 2020. 